\title{
Teratoma in the hepatoduodenal ligament: a case report
}

\author{
Ruchira Nandan, Anjan Dhua* ${ }^{*}$, Sidharth Tyagi, Vishesh Jain, Sandeep Agarwala and Veereshwar Bhatnagar
}

\begin{abstract}
Background: Teratoma of the hepatoduodenal ligament is a rare entity. Only 17 cases of hepatoduodenal ligament teratoma exist in the literature.

Case presentation: A girl with antenatally detected intraabdominal lesion was brought to us at the age of 3 years for the prime concern of progressive abdominal distension. Evaluation showed that the mass was a teratoma arising likely from the hepatoduodenal ligament. During the excision, there was an inadvertent pin-point perforation of the common bile duct. Primary repair of the common bile duct was performed. The child had an uneventful recovery.
\end{abstract}

Conclusions: The significance of anticipating complications and taking adequate measures while dissecting the porta has been emphasized in this kind of rare location of a teratoma.

Keywords: Case report, Teratoma, Hepatoduodenal ligament, Portal teratoma, Common bile duct injury

\section{Background}

Teratoma in the hepatoduodenal ligament (HDL) is an infrequent entity. Only 17 cases had been reported in the literature until this report $[1,2]$. Excision is the mainstay of treatment. Dissection at porta should be carried out with great precautions. Iatrogenic injury to the portal vein, hepatic artery, and common bile duct has all been documented before, and these can increase morbidity and mortality. We describe a case of a mature cystic teratoma of the HDL, in which the common bile duct (CBD) was injured despite all precautions. This case stresses the importance of preoperative identification of this rare entity, which, when done, should alarm the surgeon to be cautious during the operation.

\section{Case presentation}

A 3-year-old girl presented to us with abdomen distention. She had been diagnosed with a small $(2 \times 1 \mathrm{~cm})$ mass at hepatic hilum on third-trimester antenatal ultrasound. The pregnancy was uneventful. The child was

\footnotetext{
* Correspondence: anjandhua@hotmail.com

Department of Paediatric Surgery, All India Institute of Medical Sciences, Ansari Nagar, Delhi 110029, India
}

born at full term by normal vaginal delivery. She had remained asymptomatic after birth and had, therefore, not sought any medical advice. The distention of the abdomen was noticed 4 months back and was progressively increasing. It was not associated with pain, jaundice, loss of appetite, and constipation. The child had no pallor, icterus, and edema, and the vitals were all stable on examination. The right upper abdomen was distended. A firm, mobile, non-tender, globular lump of approximately $15 \times 15 \mathrm{~cm}$ was palpable in the right upper quadrant. Laboratory investigations showed a normal hemogram, liver function test, kidney function test, and alfa fetoprotein $(2.93 \mathrm{ng} / \mathrm{ml})$. Ultrasonography showed a $13 \times 8 \mathrm{~cm}$ cystic heterogeneous mass at the hepatic hilum. CECT scan abdomen showed $13 \times 11 \times 7$ $\mathrm{cm}$ mass in the subhepatic region compressing the 2nd and 3rd parts of the duodenum and displacing the gall bladder. The mass had cystic, fat components and calcifications, which were suggestive of a teratoma (Fig. 1). The liver was enlarged, but no dilatation of intrahepatic biliary radicals was seen.

Excision was planned, and during laparotomy, a $13 \times 10 \times 8 \mathrm{~cm}$ well-encapsulated ovoid mass was found in

\section{Springer Open}

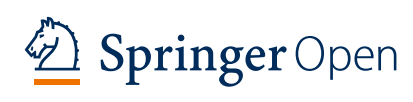

(c) The Author(s). 2021 Open Access This article is licensed under a Creative Commons Attribution 4.0 International License, which permits use, sharing, adaptation, distribution and reproduction in any medium or format, as long as you give appropriate credit to the original author(s) and the source, provide a link to the Creative Commons licence, and indicate if changes were made. The images or other third party material in this article are included in the article's Creative Commons licence, unless indicated otherwise in a credit line to the material. If material is not included in the article's Creative Commons licence and your intended use is not permitted by statutory regulation or exceeds the permitted use, you will need to obtain permission directly from the copyright holder. To view a copy of this licence, visit http://creativecommons.org/licenses/by/4.0/. 


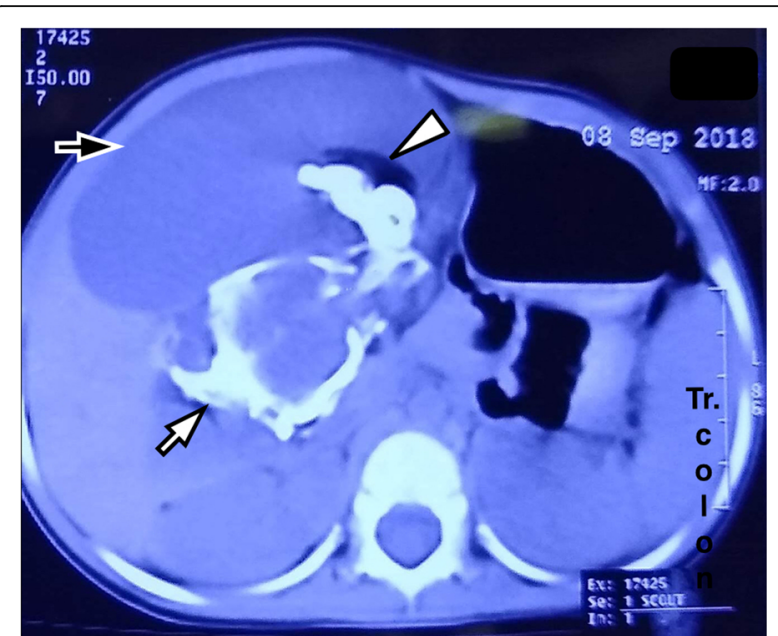

Fig. 1 Axial CECT scan section at the level of the hepatoduodenal ligament, showing the mass with cystic areas (arrow with white outline), calcification (arrow with black outline) and fatty areas (arrowhead)

the HDL. It was reaching up to the porta hepatis and was distorting its anatomy. The portal vein, the hepatic artery, and the CBD were displaced. The CBD was stretched out and had a right posterolateral relation with the mass (Fig. 2a). There was poorly defined plane with the $\mathrm{CBD}$, and while dissecting the CBD off, a pin-point perforation was noted to have occurred inadvertently. The portal vein and the hepatic artery were related to the posterior aspect of the mass and were successfully dissected off (Fig. 2b). The perforation in the CBD was assessed, and since there was no tissue loss, it was decided to perform a primary repair. The mass could be enucleated in toto without any rupture. The mass had a heterogeneous consistency with cystic and bony structures.

Postoperatively, the child was started orally on the 3rd postoperative and gradually increased. The abdominal drain had minimal serosanguinous output in the postoperative period and was removed on the 5th postoperative day. She had no fever, vitals were stable, and the wound was healthy. The child was discharged uneventfully. Mature cystic teratoma was reported on histopathology. The child has been on follow-up for 2 years with no complaints. Follow-up ultrasonography and alfa fetoprotein were normal.

\section{Discussion}

Teratoma is a germ cell tumor, which occurs at both gonadal and extragonadal sites. During organogenesis, arrest in migration of primordial germ cells to the genital ridge can lead to teratoma development in the extragonadal site. The common extragonadal sites for teratoma development are retroperitoneum, mediastinum,

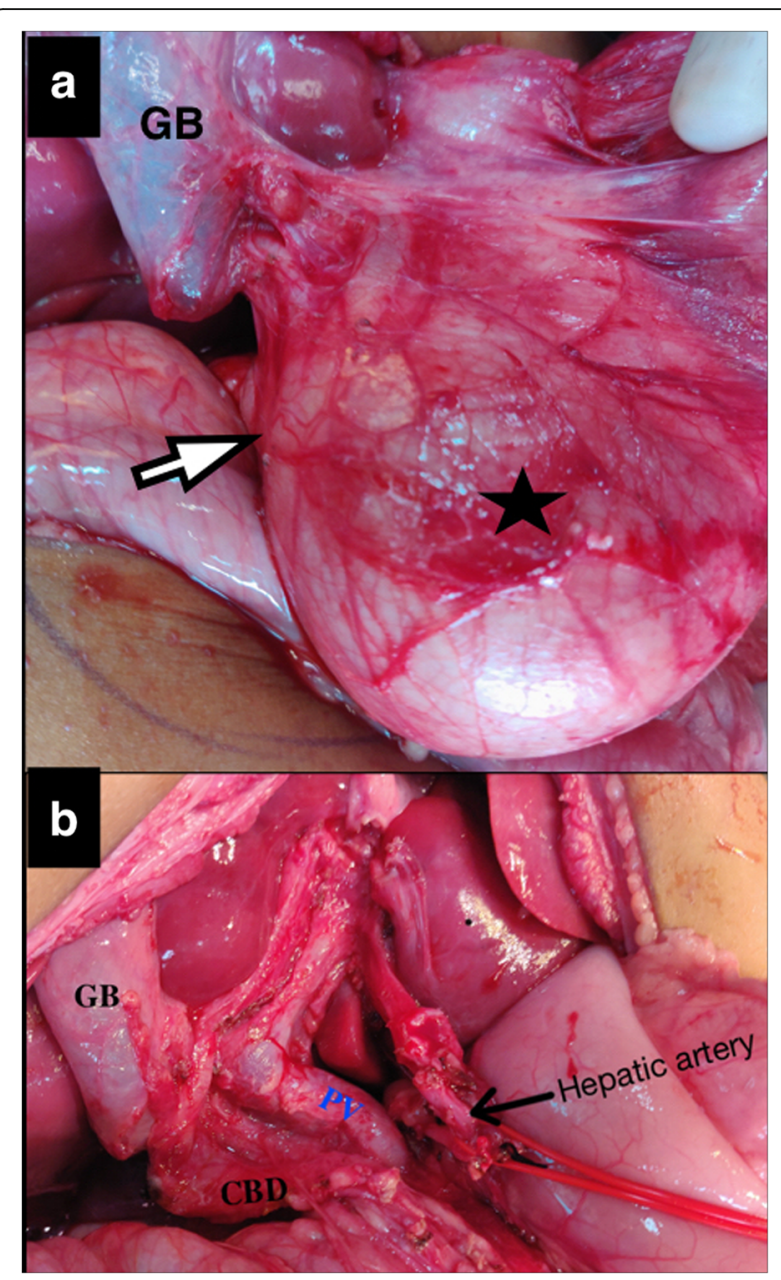

Fig. 2 a Intraoperative image showing the relations of the mass (star) with the CBD (arrow), superiorly extending up to the porta hepatis. $\mathbf{b}$ The structures in the tumor bed after the excision is completed

sacrococcygeal region, and brain. The hepatoduodenal ligament is a very rare site. Only 17 cases of teratoma in hepatoduodenal ligament have been reported in the literature $[1,2]$. It is more commonly seen in females, as in our case. Usually, the patients present in infancy with abdomen distension, pain, and jaundice [3]. Our patient had been diagnosed antenatally but remained asymptomatic initially but presented later with abdomen distension.

Ultrasonography and CT scan are helpful in the diagnosis. The characteristic findings on imaging are a mass with tissues derived from two or three germ layers. However, a definitive diagnosis requires a histological examination [3]. Teratomas contain elements from at least two of the three germ layers. Mature teratomas contain well-differentiated tissue, while immature teratomas contain neuroectoderm. Mature teratomas are more commonly seen. Of the 17 reported cases, 13 were 
mature teratomas, three immature teratomas, and in one, the histology was not reported $[1,2]$. Yolk sac elements were seen in two cases, one associated with mature teratoma and the other with immature teratoma.

Excision of teratoma is the treatment of choice. Cases have been described where during the excision, collateral damage to the CBD has occurred. This might require reconstructive procedures like choledochojejunostomy and hepaticoduodenostomy [1]. Demircan et al. had described excising the teratoma along with the distal part of the common hepatic duct [4]. Ductocystostomy and cystojejunostomy have also been reported to maintain bilo-enteric continuity [1]. Whipple's procedure has also been described and was done by Kim et al. for a polypoidal mass with components of benign cystic teratoma and endodermal sinus tumor [5]. In their case, the mass obstructed the ampulla of Vater and the CBD, and a rhabdomyosarcoma was suspected initially. Damage to the porta's blood vessels during surgery can have catastrophic consequences, both intraoperatively and postoperatively. Bagga et al. reported portal vein injury in a case that was primarily repaired. The CBD was communicating with the teratoma through a fistulous communication. Therefore, hepaticoduodenostomy was done after excision of the mass along with the distal CBD [6]. Ravikumar et al. have described a complete transection of the portal triad in a neonate. Portal vein and hepatic artery were primarily repaired, and a choledochoduodenostomy was performed to maintain the bilio-enteric continuity [7]. In our case, a pin-point perforation of CBD occurred, which was primarily repaired.

Gundapaneni et al. had reported earlier that the preoperative evaluation had provided them with a road map of the vital structures [1]. This enabled them to enucleate the mass without any collateral damage. The cases reported in the literature and the index cases highlight the importance of knowing the preoperative anatomy thoroughly to anticipate complications and therefore apply strategies to avoid them.

\section{Conclusion}

Hepatoduodenal teratoma is a rare entity. However, when encountered, it imposes a challenge upon the surgeon. Surgeons must be aware of the surgical anatomy and understand that complications may have immediate and long-term consequences if the portal triad structures are damaged.

\section{Abbreviations}

HDL: Hepatoduodenal ligament; CBD: Common bile duct; CECT: Contrastenhanced computed tomogram
Authors' contributions

Concepts: RN, AD, ST, VJ, SA and VB. Design: RN and AD. Definition of intellectual content: RN, AD, ST, VJ, SA and VB. Literature search: RN and AD. Data acquisition: RN and AD: Manuscript preparation: RN and AD. Manuscript editing: RN, AD and ST. Manuscript review: RN, ST, VJ, SA and VB. Guarantor: AD. It is also declared that all authors have read and approved the manuscript.

\section{Funding}

None

Availability of data and materials

Available upon request.

\section{Declarations}

Ethics approval and consent to participate

Since the patient concerned is a child, written informed consent was obtained from the parent.

\section{Consent for publication}

Written informed consent was obtained from the parent for publication of this case report and accompanying images.

\section{Competing interests}

The authors declare that they have no competing interests.

Received: 9 September 2020 Accepted: 5 March 2021

Published online: 03 June 2021

\section{References}

1. Gundapaneni S, Dhua AK, Jain V, Jana M, Agarwala S, Bhatnagar V. Teratoma in the hepatoduodenal ligament. J Indian Assoc Pediatr Surg. 2018;23(4): 228-31. https://doi.org/10.4103/jiaps.JIAPS_36_18.

2. Gazula S, Teja N, Mathur N, Srinivas M. Teratoma of hepatoduodenal ligament in infancy: precarious location posing a grave surgical challenge. Indian J Surg Oncol. 2020;11(Suppl 2):185-7. https://doi.org/10.1007/s13193020-01138-y.

3. Brown B, Khalil B, Batra G, Rampersad B, Bruce J. Mature cystic teratoma arising at the porta hepatis: a diagnostic dilemma. J Pediatr Surg. 2008;43(4): e1-3. https://doi.org/10.1016/j.jpedsurg.2007.11.027.

4. Demircan M, Uguralp S, Mutus M, Kutlu R, Mizrak B. Teratoma arising from anomalous common bile ducts: a case report. J Pediatr Surg. 2004;39(4):e12. https://doi.org/10.1016/j.jpedsurg.2003.12.036.

5. Kim WS, Choi BI, Lee YS, Chi JG, Park HR, Kim I, Yeon KM, Han MC. Endodermal sinus tumour associated with benign teratoma of the common bile duct. Pediatr Radiol. 1993;23(1):59-60. https://doi.org/10.1007/BF0202 0227.

6. Bagga D, Jindal B, Naredi BK, Yadav DK, Acharya SK, Mahato R, Gupta K. Portal teratoma causing obstructive jaundice in children: a rarity. J Pediatr Surg. 2012;47(7):1449-52. https://doi.org/10.1016/j.jpedsurg.2012.04.016.

7. Ravikumar VR, Rajamani G, Raju V, Sundar R, Ravikumar S, Maniam R. Teratoma arising from hepato duodenal ligament in the newborn with transection of portal vein, hepatic artery and common bile duct: a surgical challenge. J Indian Assoc Pediatr Surg. 2018;23(1):45-7. https://doi.org/10.41 03/jiaps.JIAPS_131_17.

\section{Publisher's Note}

Springer Nature remains neutral with regard to jurisdictional claims in published maps and institutional affiliations. 